Maxwell LJ, Singh JA. Abatacept for rheumatoid arthritis: A Cochrane Systematic Review. J Rheumatol 2010;37:234-45; doi:10.3899/jrheum.091066. Table 2 should appear as follows. We regret the error.

Doi:10.3899/jrheum.091066C1

Table 2. Summary of findings: comparison of abatacept (2 and $10 \mathrm{mg} / \mathrm{kg})+$ DMARD/biologic versus placebo + DMARD/biologic for RA.

\begin{tabular}{cccccc}
\hline Outcomes & \multicolumn{2}{c}{ Illustrative Comparative Risks* $(95 \% \mathrm{CI})$} & $\begin{array}{c}\text { Relative } \\
\text { Assumed Risk }\end{array}$ & Corresponding Risk & Effect \\
Placebo + & Abatacept $(2$ and & $(95 \% \mathrm{CI})$ & $\begin{array}{c}\text { No. of } \\
\text { Participants } \\
\text { (No. Studies) }\end{array}$ & $\begin{array}{c}\text { Quality of } \\
\text { Evidence } \\
\left(\text { grade }^{\dagger}\right)\end{array}$ & $\begin{array}{c}\text { Comments } \\
(95 \% \mathrm{CI})\end{array}$ \\
& $\begin{array}{c}10 \mathrm{mg} / \mathrm{kg})+ \\
\text { DMARD/Biologic }\end{array}$ & & &
\end{tabular}

\begin{tabular}{lllll}
\hline ACR 50\% improvement & 168 per 1000 & 371 per 1000 & RR 2.21 & $993(3)$ \\
Followup 12 mo & $(291$ to 474$)$ & $(1.73$ to 2.82$)$ & moderate
\end{tabular}

Absolute risk difference $21 \%$

(16\% to $27 \%)$. Relative change $=121 \%(73 \%$ to $182 \%)$. NNT $=5(4 \text { to } 7)^{4}$

Pain: measured at end Mean pain in control of study on a $100 \mathrm{~mm}$ VAS groups $=49.24 \mathrm{~mm}$ from 0 (better) to 100 (worse)

Followup 12 mo

Improvement in physical

function (HAQ: $>0.3$

increase from baseline,

$0-3$ scale)

Followup 12 mo

Achievement of low disease activity state (DAS $28<3.2$, scale $1-10)$

Followup 12 mo

Total serious adverse events Followup 6 to 12 mo

121 per 1000

127 per 1000

RR 1.05

(105 to 155$)$

(0.87 to 1.28$)$

$1425\left(1^{5}\right)$ intervention groups

$=10.71$ lower

(12.97 to 8.45

lower)

637 per 1000

(531 to 766 )

RR 1.62

$638\left(1^{6}\right)$

(1.35 to 1.95$)$

424 per 1000

RR 4.33

(2.84 to 6.59 )

$638\left(1^{6}\right)$

(278 to 646 )

$$
\text { (10 }
$$

+++-
moderate $^{1}$

\section{Change in radiographic} progression: measured by Genant-modified Sharp erosion score (increase in

\author{
Median change in \\ radiographic \\ progression in \\ control group $=$
} score means more joint damage). 0.27 units Scale 0 to 145

Followup 12 mo

Longterm serious adverse See comment events

Followup 2 yrs

\author{
Median change in \\ radiographic \\ progression in \\ intervention group \\ $=0$ units
}

See comment

$\stackrel{+++-}{\text { moderate }^{2}}$

Absolute risk difference

$-11 \%$ ( $-13 \%$ to $-8.5 \%)$.

Relative change $=-18 \%$

$(-22 \%$ to $-14 \%)$. NNT $=$ $5(4 \text { to } 6)^{4}$

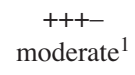

Absolute risk difference

$24 \%$ (16\% to $32 \%)$.

Relative change $=62 \%$ (35\% to $95 \%$ ).

$\mathrm{NNT}=5(4 \text { to } 7)^{4}$

Absolute risk difference 33\%

(26\% to $39 \%$ ). Relative

change $=333 \%(184 \%$ to $559 \%)$ $\mathrm{NNT}=4(3 \text { to } 5)^{4}$

Absolute risk difference $1 \%(-2 \%$ to $3 \%)$. Relative change $=5 \%(-14 \%$ to $29 \%)$. $\mathrm{NNT}=\mathrm{NA}^{4}$

Note there was no change

in the abatacept group.

$\mathrm{MD}-0.27(-0.42,-0.12)$.

Absolute risk difference $=$

$-0.2 \%$ ( $-0.3 \%$ to $-0.08 \%)$.

Relative change $=$

$-1.2 \%(-1.9 \%$ to $-0.6 \%)$

No. of patients with SAE:

Genovese $2005^{22}$ :

103/357; $23.4 \mathrm{SAE} / 100$

patient-yrs; $70 \%$ completed

the LTE. Kremer $2006^{24}$ :

149/593; $16.3 \mathrm{SAE} / 100$

patient-yrs; $90.5 \%$

completed the LTE

\footnotetext{
* The basis for the assumed risk (e.g., the median control group risk across studies) is provided in footnotes. The corresponding risk (95\% CI) is based on the assumed risk in the comparison group and the relative effect of the intervention. ${ }^{\dagger}$ Working Group grades of evidence as follows. High quality: Further research is very unlikely to change our confidence in the estimate of effect. Moderate quality: Further research is likely to have an important impact on our confidence in the estimate of effect and may change the estimate. Low quality: Further research is very likely to have an important impact on our confidence in the estimate of effect and is likely to change the estimate. Very low quality: We are very uncertain about the estimate. ${ }^{1}$ Kremer2006 $^{24}$ : Intention-to-treat analysis not performed. 9 patients in abatacept group and 5 in placebo group excluded from analysis. ${ }^{2}$ Weinblatt $2007^{20}$ : 15 people randomized were not treated and not included in analysis. ${ }^{3}$ Kremer $2003^{23}$ : Risk of attrition bias; less than $80 \%$ completion rate in treatment group at 12 months. ${ }^{4}$ Number needed to treat $(\mathrm{NNT})=$ not available (NA) when result is not statistically significant. NNT for dichotomous outcomes calculated using Cates' NNT calculator ${ }^{21}$. NNT for continuous outcomes calculated using the Wells calculator (Cochrane Musculoskeletal Group editorial office). ${ }^{5}$ Outcome based on Weinblatt $2007^{20}$. ${ }^{6}$ Outcome based on Kremer $20066^{24} .{ }^{7}$ Weinblatt $2006^{26}$; risk of attrition bias: less than $80 \%$ completion rate in the treatment group at 12 months. ${ }^{8}$ Radiographic data obtained for $90 \%$ of study participants. ${ }^{9}$ Based on 2 longterm extension studies (LTE) of RCT. Participants on placebo in the RCT switched to abatacept treatment. ${ }^{10}$ Longterm serious adverse events based on observational data. Two RCT had a LTE phase in which people in the placebo group during the RCT switched to abatacept for the LTE. RR: Risk ratio; RCT: randomized controlled trial.
} 